\title{
Effects of Horticultural Therapy on Depression and Emotional Balance of Women with Hearing Impairment
}

\author{
Ju Ran Moon ${ }^{1}$ and Yong Kweon Yoo ${ }^{1,2 *}$ \\ ${ }^{1}$ Department of Horticultural Science, College of Natural Science, Mokpo National University, Muan 58554, Korea \\ ${ }^{2}$ Institute of Natural Resource Development, Mokpo National University, Muan 58554, Korea
}

\begin{abstract}
This study was conducted to examine the effects of horticultural therapy on depression and emotional balance of women with hearing impairment. Ten women with hearing impairment registered in the Mokpo branch of the Korean Association of the Hearing Impaired were selected, and participated in the horticultural therapy program composed of 14 sessions from May 15 to July 31. The horticultural therapy program consisted of "planting tropical orchids,' 'making a dish garden,' 'making plum pickles,' 'decorating a table with flowers, 'making a hanging pot with succulent plants,' 'making pressed flowers with hydrangea,' 'making a fan with pressed flowers,' 'making a terrarium,' 'making a flower basket,' 'making a mosquito repellent spray,' 'decorating a heart-shaped cup with flowers,' 'making a natural herbal soap,' 'making a hydrangea bouquet' and 'making watermelon salad.' The depression and emotional balance scales were used to examine the effects of the program and the pre- and post-program scores were compared. The mean value of depression statistically significantly decreased from 49.0 points before the program to 43.9 points after the program. In addition, the mean value of emotional balance statistically significantly increased from 0.3 points before the program to 2.3 points after the program. The activity of drawing a picture after each session was effective in reducing depression and improving positive emotional balance by expressing emotions through pictures. The programs preferred by women with hearing impairment included 'making plum pickles,' 'making pressed flowers with hydrangea,' 'planting tropical orchids,' 'making a mosquito repellent spray, 'making a natural herbal soap,' and 'making watermelon salad.' In conclusion, horticultural therapy programs were effective in reducing depression and improving emotional balance of women with hearing impairment.
\end{abstract}

Keywords: emotional expression, painting activity, program preference

\section{Introduction}

Hearing impairment is an inability to hear sounds including spoken languages due to partial or total damage to auditory organs, which limits the function of daily communication (Son, 2003). According to the Census of the Disabled in 2017 conducted by the Ministry of Health and Welfare, the total population of the disabled in Korea was 2,668,411, and the number of those with physical disabilities was 1,242,785 (46.6\%); those with brain lesions, 258,121 (9.7\%); those with hearing impairment, 256,018 (9.61\%); and those with visual impairment, 252,046 (9.4\%). People with hearing impair-

Received: December 12, 2018, Revised: January 4, 2019, Accepted: February 11, 2019

First author: Ju Ran Moon, E-mail: ran9591@hanmail.net, (D) https://orcid.org/0000-0001-8761-2808

*Corresponding author: Yong Kweon Yoo, E-mail: yooyong@mokpo.ac.kr, (1) https://orcid.org/0000-0001-6884-163X 
ment accounted for the third largest share of the total population of the disabled (Ministry of Health and Welfare, 2017). Those with hearing impairment show symptoms of depression due to reduced hearing ability, and also experience difficulties and conflicts in interacting with others and doing social activities due to limited communication, which makes it difficult for them to express their opinions or feelings, causing psychological and emotional problems such as withdrawal, anxiety and lack of confidence (Choi, 2004; Noh and Kim, 2008). Women with hearing impairment experience more complicated psychological problems and conflicts due to discrimination and prejudice caused by disorders (Han, 2006), and they show a higher level of depression than men, and, if left untreated, it may lead to suicide (Kim, 2013; Song, 2013). In addition, their inability to hear sounds and express their intention in language has a bad influence on their mental development, and further isolates them, interrupting normal interactions between individual and society (Go, 2009).

Horticultural therapy pursues not only psychological and emotional adaptability but also improvements in the quality of life through horticultural activities. Relf and Lohr (2003) pointed out that people can have hope for their future and develop creativity and ability to self-express while watching that the plants they raise grow well. It was reported that horticultural therapy was effective in suppressing the anger of those with physical disabilities through activities of contacting plants, and in establishing positive self-images through a sense of accomplishment and in the process of expressing joy (Lee et al., 2008). Materials such as flowers and plants appeal to the emotions of the disabled, and contributes to their emotional development (Sin and Lee, 2010; Lee et al., 2013), and they can have opportunities to express themselves by selecting various flower materials and freely decorating with flowers, which effectively improves a sense of confidence and emotional balance (Kim and Ahn, 2008; Lee, 2011). In addition, activities of making and completing flower decorations and household items were found to give those with intellectual disabilities a sense of confidence and hope, which eliminated fear and anxiety of failure and reduced symptoms of depression (Park et al., 2006).

Many studies have been conducted on the effects of horticultural therapy on people with physical disabilities, but only few studies focused on those with hearing impairment, except the case study on the cognitive emotions and motor development of children with hearing impairment (Jhun, 2016) and the study on the effects of horticultural therapy on the confidence, psychology and sociality of adults with hearing impairment (Lee, 2008). Against this backdrop, this study aimed to examine the effects of a horticultural therapy program on the depression and emotional balance of women with hearing impairment.

\section{Research Methods}

\section{Subjects}

In this study, a horticultural therapy program was performed for subjects selected among women with hearing impairment registered in the Mokpo branch of the Korea Association of the Hearing Impaired who expressed their intention to participate in a horticultural therapy program. The general characteristics of the subjects were as shown in Table 1. A total of 10 participants (one in the 20s, one in the 30s, five in the 50s, two in the 60s, one in the 70s) was selected, and those in their 50s accounted for the largest share. In terms of disability rating, the number of those with Grade 3 and 2 hearing impairment was two and eight respectively, and in terms of marriage status, all the participants except the one in the 20 s were married, and had 1-3 children. The number of those who were uneducated was the highest (seven participants), and one graduated from elementary school, high school and 2-year college. All the subjects selected in this study used sign language, and only Subjects D and H used both sign and spoken languages. 
Table 1. Characteristics of women with hearing impairment who participated in this program

\begin{tabular}{|c|c|c|c|c|c|c|c|}
\hline \multirow{2}{*}{ Subject } & \multirow{2}{*}{ Age } & \multirow{2}{*}{$\begin{array}{c}\text { Grade of } \\
\text { impairment }^{2}\end{array}$} & \multirow{2}{*}{$\begin{array}{l}\text { Married } \\
\text { (Yes/No) }\end{array}$} & \multirow{2}{*}{$\begin{array}{l}\text { Number of } \\
\text { children }\end{array}$} & \multirow{2}{*}{ Degree of education } & \multicolumn{2}{|c|}{ Method of communication } \\
\hline & & & & & & Sign & Oral \\
\hline $\mathrm{A}$ & 76 & 2 & Yes & 3 & Uneducated & $\circ$ & \\
\hline B & 63 & 3 & Yes & 3 & Uneducated & $\circ$ & \\
\hline $\mathrm{C}$ & 69 & 2 & Yes & 2 & Uneducated & $\circ$ & \\
\hline $\mathrm{D}$ & 38 & 2 & Yes & 1 & High school & $\circ$ & $\circ$ \\
\hline E & 59 & 2 & Yes & 2 & Uneducated & ० & \\
\hline $\mathrm{F}$ & 54 & 3 & Yes & 2 & Uneducated & $\circ$ & \\
\hline $\mathrm{G}$ & 57 & 2 & Yes & 4 & Uneducated & ○ & \\
\hline $\mathrm{H}$ & 25 & 2 & No & 0 & 2 year college & ० & ○ \\
\hline I & 52 & 2 & Yes & 1 & Elementary school & ० & \\
\hline $\mathrm{J}$ & 57 & 2 & Yes & 1 & Uneducated & $\circ$ & \\
\hline
\end{tabular}

${ }^{\mathrm{z}}$ Grade by welfare law for disabled person in Korea Ministry of Government Legislation (KMGL). Retrieved from http://www.law.go.kr/lsInfo P.do?lsiSeq=206154\&efYd=20190101\#0000.

\section{Design of horticultural therapy program}

\section{Design of horticultural therapy program}

Interviews with therapists, sign interpreters and subjects were conducted to identify the characteristics and degree of disabilities and thus to design a horticultural therapy program based on the results. The designed horticultural therapy program was provided for women with hearing impairment from May 15 to July 31, a total of 14 sessions, 2 hours per session. The horticultural therapy program was provided by a team composed of one therapist, one therapist assistant, and one sign interpreter. In this study, an one-group pretest-posttest design was used to compare the pretest and posttest averages of the experimental group.

\section{Contents of horticultural therapy program}

The results of the pre-interviews and surveys showed that the majority of the subjects had mild depression, and negative emotional balance. Considering that the horticultural therapy program was for women with hearing impairment, the program was composed of indoor activities that are simple and can raise their interest and curiosity in order to reduce depression and to build positive emotional balance through activities of drawing a picture and expressing emotions. The program was composed of a total of 14 sessions, and was divided into the early, mid and late stages (Table 2). With the aim of building a sense of confidence and expressing emotions in the early stage, each session focused on the followings. In the Session 1, subjects planted tropical orchids and were encouraged to express their feelings while watching colorful flowers, and, in the Session 2, they made a dish garden to improve their understanding of air purifying plants and cognitive ability, and to express their emotions. In the Session 3, subjects were encouraged to express their depressive emotions while making plum pickles, to relieve daily mounting stress while smashing plums to separate pulp and seeds, and to have a sense of accomplishment and the joy of improving health through the outcomes of each activity. In the Session 4 , they decorated a table with flowers and were encouraged to express their feelings about the decorations. Activities in the mid stage aimed to reduce depression and improve emotional balance. In the Session 5, subjects made a hanging pot with succulent plants and drew a picture to express their feelings that cannot be expressed in language and thus to have a sense 
Table 2. Contents of horticultural therapy program in this study

\begin{tabular}{|c|c|c|c|}
\hline Session & Date & Contents & Purpose \\
\hline 1 & $05 / 15$ & Planting tropical orchids & \multirow[b]{2}{*}{ - Confidence building } \\
\hline 2 & $05 / 29$ & Making a dish garden & \\
\hline 3 & $06 / 12$ & Making plum pickles & \multirow[t]{2}{*}{ - Emotional expression } \\
\hline 4 & $06 / 20$ & Decorating table with flowers & \\
\hline 5 & $06 / 24$ & Making a hanging pot with succulent plants & \multirow{5}{*}{$\begin{array}{l}\text { - Decrease of depression } \\
\text { - Increase of emotional } \\
\text { balance }\end{array}$} \\
\hline 6 & $06 / 26$ & Making pressed flowers with hydrangea & \\
\hline 7 & 07/03 & Making a fan with pressed flowers & \\
\hline 8 & 07/08 & Making a terrarium & \\
\hline 9 & $07 / 10$ & Making a flower basket & \\
\hline 10 & $07 / 17$ & Making a mosquito repellent spray & \multirow{3}{*}{$\begin{array}{l}\text { - Recognition of myself } \\
\text { role and strengths }\end{array}$} \\
\hline 11 & $07 / 22$ & Decorating a heart-shaped cup with flowers & \\
\hline 12 & $07 / 24$ & Making a natural herbal soap & \\
\hline 13 & $07 / 29$ & Making a hydrangea bouquet & \multirow[t]{2}{*}{$\begin{array}{l}\text { - Regulation of depression } \\
\text { and emotion balance }\end{array}$} \\
\hline 14 & $07 / 31$ & Making watermelon salad & \\
\hline
\end{tabular}

of confidence and accomplishment. In the Session 6, subjects made pressed flowers using hydrangea. The activity of making pressed flowers is known to be effective in relieving depression and aggressive feelings and communicating emotions (Kim and Yoo, 2005). In the Session 7, subjects made a fan with pressed flowers to improve their ability to utilize objects through the activity. They made creative works to reduce depression using colorful flowers and plants including terrariums in the Session 8 and flower baskets in the Session 9. The late stage focused on improving subjects' understanding of their roles and strengths, and controlling depression and emotional balance. In the Session 10, subjects made a mosquito repellent spray and sprayed it to the arms and legs of other subjects in order to increase positive emotions between them. In the Session 11, subjects decorated a heart-shaped cup with flowers to express their emotions, and, the Session 12 focused on improving their sensory function through the activity of making a natural herbal soap and smelling the scent of herbs. In the Session 13, subjects were encouraged to express their feelings by making a hydrangea bouquet, and, in the Session 14, they made watermelon salad and expressed the emotions of self-respect and consideration for others.

Prior to conducting each session, the interest and participation of subjects were induced by providing explanations about the program to improve their visual understanding using visual materials for 30 minutes. The program was composed of 10 minutes of the introduction activity, 40 minutes of the main activity, 10 minutes of the wrap-up activity and 30 minutes of drawing a picture. In order to continuously induce their interest, subjects were encouraged to express their feelings about the program during the introduction activity, to focus on experiencing the program during the main activity, and to share their intention and feelings about their outcomes during the wrap-up activity. Anything difficult or dangerous for subjects with hearing impairment was assisted by assistants to ensure they can complete each activity and obtain outcomes in each session, and thus have a sense of accomplishment. After each session, they were instructed to draw a picture about the activity of the session. 


\section{Assessment tools}

To assess the level of depression, the self-rating depression scale (SDS) that was developed by Zung (1965) and was translated into Korean (Woo, 2012) was used, and Cronbach's $\alpha$ was .82. This scale is used to assess depression based on the frequency of depression symptoms, and is composed of a total of 20 questions on three basic conditions including sustained emotional state, physiological symptoms and psychological conditions. The total score of the scale ranged between 20 and 80, and those who score lower than 50 are assessed as normal. Those who score less than 60 are assessed as mild depression, and those who score less than 70 are assessed as moderate depression and need counseling of experts for mental health. Those who score 70 or higher are assessed as severe depression and need counseling and treatment of experts.

The scale of emotional balance used in this study was the one which was developed by Bradburn (1969) and was composed of 10 questions (five questions of positive emotions and five questions of negative emotions), and the Cronbach's $\alpha$ of the scale was .76 (positive questions) and .67 (negative questions). The score of emotional balance is calculated by subtracting the total score of negative questions from that of positive questions, and ranges between -5 and 5 . The higher the score, the higher psychological balance.

Drawing a picture is a tool for people with hearing impairment who have difficulties in communicating to self-express what they cannot express in language and to relieve psychological withdrawal symptoms (Malchiodi, 2003). In this study, subjects were instructed to draw a picture to express what they felt during the activities of horticultural therapy after each session ended. Out of the pictures drawn in 14 sessions, those drawn in the Session 2 (early stage), 5 (mid stage) and 10 (late stage) were selected and sent to an expert in the Myoungji Art Therapy Institute to evaluate expressions and psychological and emotional states.

After completing the whole horticultural therapy program, subjects were surveyed about which session they preferred ( 2 for 'good,' 1 for 'medium' and 0 for 'not good'). The scores of sessions were added up, and the total score ranged between 20 and 0 .

\section{Analysis methods}

The collected data in this study were statistically analyzed using the SPSS Win 21 program, and significant differences between before and after performing the horticultural therapy program were analyzed using the Wilcoxon signed-rank test.

\section{Results and Discussion}

\section{Changes in depression of women with hearing impairment after the horticultural therapy program}

Changes in the depression of women with hearing impairment after the horticultural therapy program were surveyed, and the results are as shown in Table 3. Out of 10 subjects, seven subjects showed a decrease in depression by 1.3-16.3, and the score of Subjects $\mathrm{H}$ and $\mathrm{J}$ increased by 2.5 points. Before performing the horticultural therapy program, six subjects were assessed to have mild depression, and four subjects were normal. After performing the program, the number of those with mild depression was two, and eight subjects were assessed as normal, indicating improvements in depression. The average score of the 10 subjects decreased by 5.1 from 49.0 before the horticultural therapy program to 43.9 after the program, showing a statistically significant decrease (Table 4).

Yun et al. (2009) reported that the depression of participants in a horticultural therapy program decreased after partici- 
Table 3. Differences in depression of women with hearting impairment between pre- and post-horticultural therapy

\begin{tabular}{lccc}
\hline Subject & Pre-HT $^{2}(\mathrm{~A})$ & Post-HT (B) & Difference (B-A) \\
\hline A & 55.0 & 46.3 & -8.8 \\
B & 55.0 & 38.8 & -16.3 \\
C & 42.5 & 42.5 & 0.0 \\
D & 56.3 & 50.0 & -6.3 \\
E & 42.5 & 35.0 & -7.5 \\
F & 36.3 & 35.0 & -1.3 \\
G & 50.0 & 43.8 & -6.3 \\
H & 55.0 & 57.5 & 2.5 \\
I & 52.5 & 42.5 & -10.0 \\
J & 45.0 & 47.5 & 2.5 \\
\hline
\end{tabular}

Note. The depression score ranges from 20 to 80 .

${ }^{\mathrm{z}}$ Horticultural therapy.

Table 4. Statistical comparison of pre- and post-horticultural therapy in depression of women with hearing impairment

\begin{tabular}{|c|c|c|c|}
\hline \multirow{2}{*}{ Item } & \multicolumn{2}{|c|}{$\mathrm{M} \pm \mathrm{SD}$} & \multirow[b]{2}{*}{$p$} \\
\hline & Pre-HT ${ }^{\mathrm{z}}$ & Post-HT & \\
\hline Depression & $49.0 \pm 7.0$ & $43.9 \pm 6.9$ & $.035^{*}$ \\
\hline
\end{tabular}

${ }^{\mathrm{z}}$ Horticultural therapy.

*Significant at $p<.05$ level by Wilcoxon signed-rank test.

pating in activities of watching and smelling colorful flowers, and decorating with flowers. Elderly people with visual impairment showed improvements in their self-esteem composed of 'self-values,' 'talents,' 'a sense of failure, 'ability,' 'pride,' 'a sense of satisfaction' and 'respect' through horticultural therapy, and their depression was reduced (Kim et al., 2014). Elderly people and those with dementia who actively participated in a horticultural therapy program and various activities of creation showed a decrease in depression and an increase in the satisfaction of living, indicating psychological and social effects ( $\mathrm{Ra}, 2001)$. Horticultural therapy programs conducted for elderly people with visual or hearing impairment were found to improve their skills and work adjustment through various horticultural activities, to increase the level of self-esteem such as self-values, pride and a sense of satisfaction, and thus to reduce depression (Kim et al., 2014; Lim and Park, 2016). In this study, personal relations between subjects improved through communication between them during activities including making a dish garden, making plum pickles, decorating a table with flowers, making a terrarium and making a hydrangea bouquet, and their self-esteem improved by completing several works on their own, reducing depression.

\section{Changes in emotional balance of women with hearing impairment after the horticultural therapy program}

Changes in the emotional balance of women with hearing impairment after the horticultural therapy program were surveyed, and the results are as shown in Table 5 . Out of 10 subjects, five subjects showed negative scores $(-1$ or -2$)$ in 
emotional balance before the program, and the rest five subjects scored 1-3 points. After the program, Subjects E, F and $\mathrm{H}$ did not show any change, while the score of the rest seven subjects increased by 1-5 points. In particular, the score of Subject A increased from -1 to 4, and that of Subject J increased from -2 to 3, showing the highest change in emotional balance. The average emotional balance score of the 10 subjects increased by 2.0 from 0.3 before the horticultural therapy program to 2.3 after the program, showing a statistically significant increase (Table 6).

It was reported that horticultural therapy activities for elderly patients with brain diseases enabled them to have a sense of emotional stability through activities of recreating beauty through flower decorations, and to express their emotions and improve their ability to control emotions through feedbacks between therapists and participants (Yun et al., 2009). In addition, a horticultural therapy program was found to increase the sense of satisfaction and accomplishment of those with senile diseases (Lee et al., 2000), and it was also reported that floricultural decorations and leaf decorations reduced negative emotions, having a positive impact on humans' emotions (Adachi, 2000). Kim and Yoo (2005) found that a horticultural therapy program for elderly patients with brain diseases satisfied their five senses through colorful flowers and herbal scents, reduced anxiety and negative tendencies, and thus achieved emotional stability and emotional balance.

People with hearing impairment showed improvements in interest and assistance, language communication, selfconception and independence, and desire-impulse adaptability through horticultural activities, and achieved emotional stability by frequently contacting and cultivating plants (Lee, 2008). In this study, women with hearing impairment were

Table 5. Differences in emotional balance of women with hearting impairment between pre- and post-horticultural therapy

\begin{tabular}{lccc}
\hline Subject & Pre-HT $^{z}(\mathrm{~A})$ & Post-HT (B) & Difference (B-A) \\
\hline A & -1 & 4 & 5 \\
B & -1 & 0 & 1 \\
C & -1 & 2 & 3 \\
D & -2 & 1 & 3 \\
E & 1 & 1 & 0 \\
F & 3 & 3 & 0 \\
G & 2 & 4 & 2 \\
H & 1 & 1 & 0 \\
I & 3 & 4 & 1 \\
J & -2 & 3 & 5 \\
\hline
\end{tabular}

Note. The score of emotional balance ranges between -5 and 5 . The higher the score, the higher psychological balance.

${ }^{\mathrm{z}}$ Horticultural therapy.

Table 6. Statistical comparison of pre- and post-horticultural therapy in emotional balance of women with hearing impairment

\begin{tabular}{lccc}
\hline Item & & $\mathrm{M} \pm \mathrm{SD}$ & \\
& Pre-HT $^{\mathrm{z}}$ & Post-HT & $p$ \\
\hline Emotional balance & $0.3 \pm 1.9$ & $2.3 \pm 1.5$ & $.014^{*}$ \\
\hline
\end{tabular}

${ }^{\mathrm{z}}$ Horticultural therapy.

*Significant at $p<.05$ level by Wilcoxon signed-rank test. 
encouraged to express their feelings in sign language about activities including planting tropical orchids, pressing hydrangea, making a fan with pressed flowers, making a flower basket and making a natural herbal soap, and their ability to express and control emotions was found to be improved. In addition, subjects had a sense of satisfaction and accomplishment through activities of making beautiful flower decorations, and showed positive changes in emotional responses, indicating that those activities were effective in improving the overall emotional balance of subjects.

\section{Evaluation of pictures}

After the horticultural therapy program, subjects were instructed to express the activity of each session by drawing a picture, and, out of the pictures drawn in 14 sessions, those drawn in the Session 2 (early stage), 5 (mid stage) and 10 (late stage) were selected and sent to an expert in the Myoungji Art Therapy Institute to evaluate the pictures (Figure 1). Thin drawing lines and muted colors in the pictures of Subject A gradually turned to detailed sketching. Subject A showed the expanded scope of her thinking and an increase in the level of confidence, more actively expressing emotions, which coincides with the result that the score of emotional balance increased by 5 points after the program (Table 5). Subject $\mathrm{C}$ drew stiff lines in the early stage, but drew soft lines and harmonious colors in the late stage, resolving internal conflicts. The subject did not show any difference in the level of depression between before and after the program, but the emotional balance score increased by 3 points after the program, indicating that the score increased as internal conflicts were resolved. Subject $\mathrm{F}$ tended to use the upper part of drawing paper in the early stage, but gradually placed objects in a balanced way and used vivid and various colors, indicating that depression was reduced. This coincided with the result that the score of depression decreased by 1.3 points after the program compared to the level before the program (Table 3). Subject G gradually structured objects over time, expressed positive emotions using colors in a harmonious way and drawing flowers, and expressed her desire to be protected through a mosquito repellent spray. The score of depression of Subject $\mathrm{G}$ decreased by 6.3 points after the program, and the score of emotional balance increased by 2 points after the program, indicating that depression and emotional balance improved. Subject I expressed vivid colors and various aspects of plants, and showed that her interest in herself and people surrounding her increased by drawing a house. These expressions resulted in a significant decrease in the score of depression (down by 10 points) after the program, and the score of emotional balance increased by 1 point.

In this study, subjects were instructed to draw a picture after each session ended in order to introduce the effects of art therapy. Art therapy is a method of discovering things that were lost, distorted and suppressed through visual media and understanding and self-expressing their own issues through nonlinguistic means (Kim, 2002). The process of drawing a picture reduces dependence, contributes to the creation of positive ego and relieve fear of failure (Yoon et al., 2003). People can also express their inner side and relieve inner tension by drawing a picture, instead of using language (Han and Chung, 2005). Chiang et al. (2004) introduced the activity of drawing pictures to a horticultural therapy program for children with developmental disorders as a method of expressing what they experienced, and reported that subjects started to use various colors, which led to the diversification of emotions from a psychological perspective. In addition, as art activities were performed after finishing each horticultural activity under the program, their synergistic effect seemed to be expanded.

In this study, women with hearing impairment were able to depict plants in more detail and to use more colors in the late stage, and their ability to utilize space improved. Through activities of drawing pictures, subjects were able to freely express their inner emotions, and to control their own conflicts, which reduced depression and positively affected emotional balance through diversified emotions. 
Session 2

Subject A

Subject C

Subject F

Subject G

Subject I
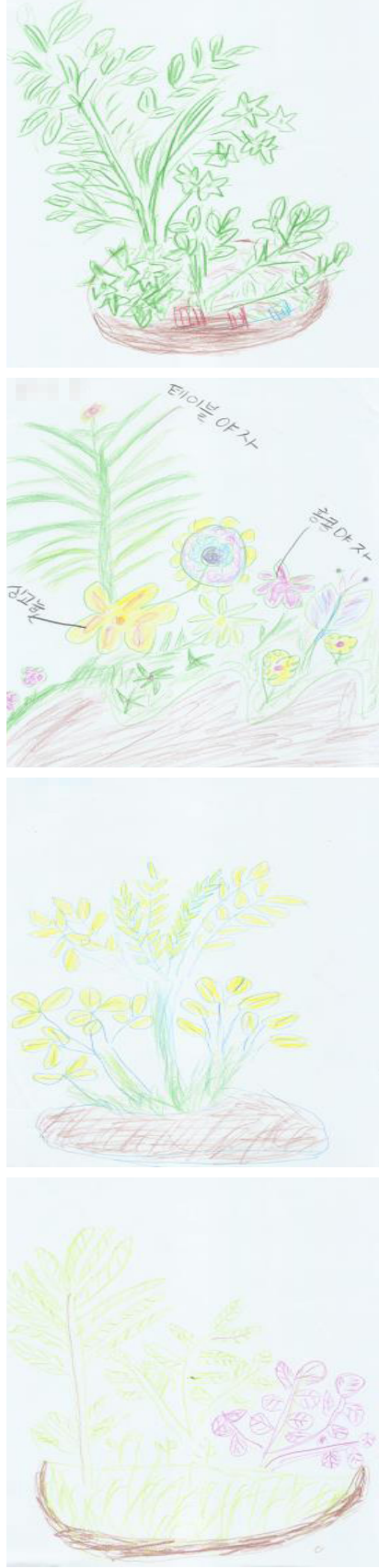

Session 5
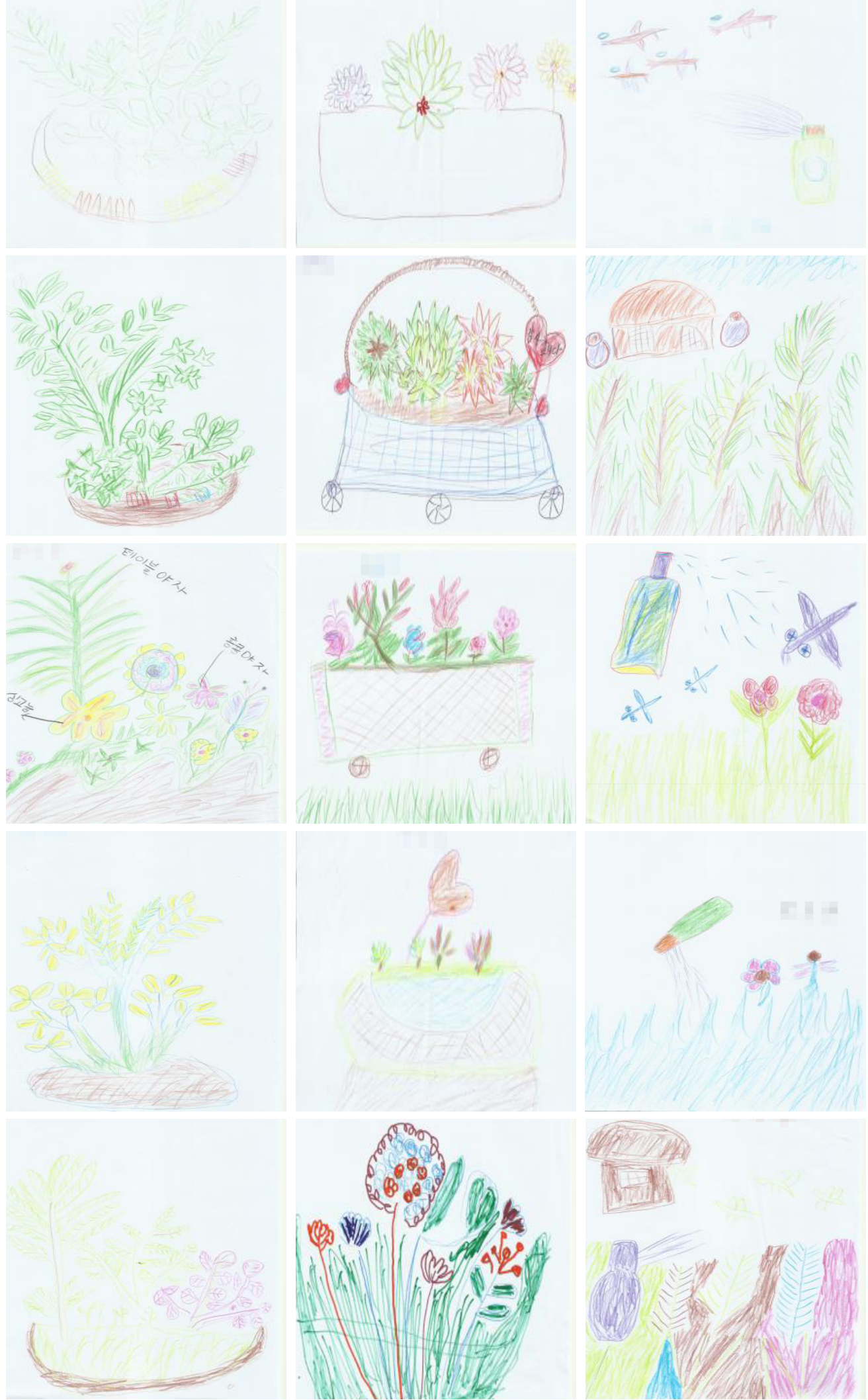

Figure 1. Drawings collected for evaluation after Session 2, 5, and 10 from Subject A, C, F, G, and I. 


\section{Preference for horticultural therapy activities}

After each session of the horticultural therapy program for women with hearing impairment ended, their preference for the program was surveyed. Out of the 14 sessions, subjects' preference for the activity of making plum pickles in the Session 3 and that of pressing hydrangea in the Session 6 was the highest (20 points) (Figure 2), which can be attributed to positive emotions that were created as female subjects who were interested in promoting the health of their family members made pickles using plums in season. During the activity of pressing colorful hydrangea, subjects were excited as if they went back to when they were a girl, and they participated in the activity in an active and enthusiastic manner, which seemed to result in a high preference level. There were five activities that scored 19 points including planting tropical orchids in the Session 1, making a dish garden in the Session 2, making a mosquito repellent spray in the Session 10, making a natural herbal soap in the Session 12, and making watermelon salad in the Session 14. The activities of making a fan with pressed flowers in the Session 7 and making a hydrangea bouquet in the Session 13 scored 18 points. The activity of making a hanging pot with succulent plants scored 17 points, and those of making a terrarium in the Session 8 and making a flower basket in the session 9 scored 16 points. The activities of decorating a table with flowers in the Session 4 and decorating a heart-shaped cup with flowers in the Session 11 showed the lowest preference level (15 points). Subjects felt sorry for the fact that fresh flowers used to decorate a table and hear-shaped cup would wither over time and have to be thrown out eventually, which seemed to result in the lowest preference level.

It was reported that bright and vivid colors of cut flowers and materials used in horticultural therapy like red and yellow were effective in reducing the depression of elderly people (Kim and Joo, 2008). In addition, elderly patients with

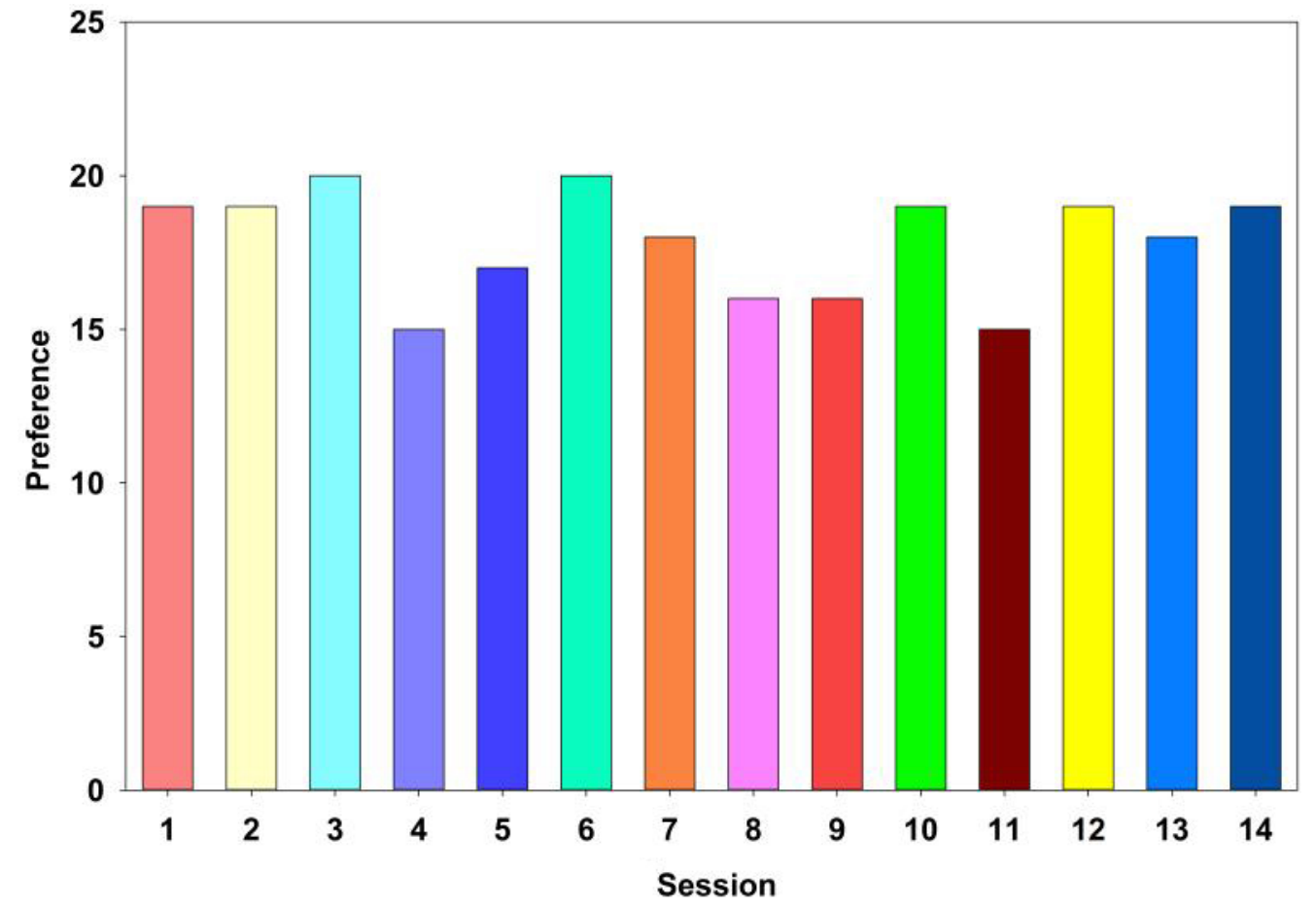

Figure 2. Preference of horticultural therapy activities performed for women with hearing impairment. The content of each session is as follows: 1 = planting tropical orchids; 2 = making a dish garden; 3 = making plum pickles; $4=$ decorating table with flowers; $5=$ making a hanging pot with succulent plants; $6=$ making pressed flowers with hydrangea; 7 = making a fan with pressed flowers; $8=$ making a terrarium; $9=$ making a flower basket; $10=$ making a mosquito repellent spray; $11=$ decorating a heart-shaped cup with flowers; $12=$ making a natural herbal soap; 13 = making a hydrangea bouquet; $14=$ making watermelon salad. 
dementia or stroke were found to be most excited about the activity of making a dish garden among other horticultural therapy activities, and they showed the most active attitude and the highest emotional response to the activity of making a flower basket (Lee et al., 2000). In an early study on the preference of students with hearing impairment for flower colors, they preferred red, orange and yellow-colored begonia flowers, and unlike general students they tended to particularly prefer green (Oh et al., 1999). In this study, women with hearing impairment also preferred activities of pressing hydrangea flowers, making a dish garden, making pressed flowers and making a flower basket with hydrangea, which can be attributed to bright and vivid colors of hydrangea and green plants used in dish gardens.

\section{Conclusion}

People with hearing impairment show psychological and emotional problems as they are unable to freely express their opinions and emotions due to limited communication. They also experience difficulties in social activities due to lack of interactions with others, which results in melancholy and emotional imbalance. In this study, various horticultural therapy activities which women with hearing impairment can easily participate in indoor were performed, and their effects on the depression and emotional balance were examined. A total of 14 sessions of the horticultural therapy program designed in this study were provided for 10 women with hearing impairment registered in the Mokpo branch of the Korea Association of the Hearing Impaired from May 15 to July 31. The program was composed of planting tropical orchids, making a dish garden, making plum pickles, decorating a table with flowers, making a hanging pot with succulent plants, pressing hydrangea flowers, making a fan with pressed flowers, making a terrarium, making a flower basket, making a mosquito repellent spray, decorating a heart-shaped cup with flowers, making a flower bouquet with hydrangea and making watermelon salad. The level of depression and emotional balance was measured using a scale before and after performing the program, and subjects were instructed to draw a picture after each session in order to evaluate their emotional expressions and psychological and emotional changes. In addition, horticultural therapy activities preferred by women with hearing impairment were surveyed.

Over the course of the horticultural therapy program, personal relations between subjects improved through communication between them. The outcomes they obtained after each session ended seemed to improve their self-esteem and thus reduce depression. The level of depression of seven subjects decreased after the program. The score of depression decreased by 5.1 points from 49.0 points before the program to 43.9 points after the program, showing a statistically significant decrease. As subjects were instructed to express their feelings about activities after each session ended, their ability to control emotions seemed to increase. Activities of making decorations with beautiful flowers improved their sense of satisfaction and accomplishment, and their positive effects on emotional response seemed to improve emotional balance. After the program, the emotional balance of seven subjects was found to be improved, and the score increased by 2.0 points from 0.3 points before the program to 2.3 points after the program, showing a statistically significant decrease.

Entering the late stage of the horticultural therapy program, subjects tended to depict plants in more detail and to use more colors in their pictures. As they expressed their emotions through the activity of drawing a picture, their depression seemed to be reduced and their emotional balance also seemed to be positively affected.

Horticultural therapy activities preferred by women with hearing impairment include pressing hydrangea flowers, making plum pickles, planting tropical orchids, making a mosquito repellent spray, making a natural herbal soap and making watermelon salad. Various horticultural therapy activities and drawing a picture were found to be effective in reducing the depression of and improve the emotional balance of women with hearing impairment.

Due to several limitations in reality, women with hearing impairment who lived in a certain region were selected in 
this study, and, for the reason, their age range varied from the 20s to 70s. During interviews with women with hearing impairment in the stage of evaluation, they tended not to expose their problems, and thus it was difficult to accurately diagnose them. In addition, this study was conducted among women with hearing impairment who lived in a certain region, Mokpo-si only, which reveals a regional limitation in this study. It will be necessary to conduct in-depth follow-up studies targeting women with hearing impairment in a nationwide scale.

\section{References}

Adachi, M., C.L.E. Rohde, and A.D. Kendle. 2000. Effect of floral and foliage displays on human emotions. HortTechnlogy 10(1):59-63. https://doi.org/10.21273/HORTTECH.10.1.59

Bradburn, N.M. 1969. The structure of psychological well-being. Chicago, IL: Aldine Publishing Co.

Chiang, M.H., J.M. Kim, S.J. Yoon, and Y.J. Chung. 2004. Horticultural therapy and drawing activity for disabled children. J. Korean Soc. Plants People Environ. 7(4):58-64.

Choi, H.H. 2004. The effects of group art therapy on the social-emotional development of children with hearing impairment. Master's thesis, Wonkwang University, Iksan, Korea.

Go, C.H. 2009. A study on university students' perception of disabilities for hearing-impaired persons in situations of personal and social relations. Master's thesis, Daegu University, Daegu, Korea.

Han, E.S. and Y.J. Chung. 2005. A study on experience of art therapy on women with hearing impairments. J. Psychother. [Seoul Women's University] 5(2):59-76.

Han, Y.S. 2006. A hermeneutic phenomenological study on experience of art therapy on women with hearing impairments. Master's thesis, Seoul Women's University, Seoul, Korea.

Jhun, Y. 2016. A case study on the influence of the recognition emotional and motor development through the horticultural therapy on the preschool children with hearing impairment. Doctoral dissertation, Dankook University, Seoul, Korea.

Kim, H.S. and Y.K. Yoo. 2005. Effects of horticultural therapy using the press flower on the powerlessness and interpersonal relationship in woman schizophrenia patients. J. Korean Soc. Plants People Environ. 8(1):32-37.

Kim, H.Y. and E.Y. Joo. 2008. Effect of horticultural therapy on the depression of the old adults and research on the preference of material color. J. Korean Soc. People Plants Environ. 11(1):1-6.

Kim, H.Y. and J.Y. Ahn. 2008. Effects of horticultural therapy on hand function and emotional balance of the crippled disordered. J. Korean Soc. People Plants Environ. 11(3):83-89.

Kim, M.J., I.H. Kim, N.R. Lee, K.Y. Hur, and K.O. Choi. 2014. Effects of horticultural therapy on depression and self-esteem of elderly visual disabilities. J. Korean Soc. People Plants Environ. 17(6):433-440. https://doi.org/10.11628/ksppe.2014.17.6.433

Kim, M.R. 2013. Effects of horticultural therapy on the mental health high-risk group. Doctoral dissertation, Pusan National University, Busan, Korea.

Kim, T.E. 2002. Hermeneutic phenomenological study on experience of group art therapy with the children of single parent in low income. Master's thesis, Seoul Women's University, Seoul, Korea.

Lee, M.H, S.H. Park, S,Y. Lim, E.K. Jeong, and J.K. Suh. 2000. A study for preference of older adult about horticultural therapy programs. J. Korean Soc. Plants People Environ. 3(4):31-37.

Lee, M.J. 2011. Effects of horticultural therapy on social skill and self-expression of the intellectually challenged people. J. Korean Soc. People Plants Environ. 14(4):199-205.

Lee, M.J., W. Oh, and J.S. Jang. 2013. Effects of horticultural activities socio-emotional development and self-expression of children with development disabilities. J. Korean Soc. People Plants Environ. 16(6):353-359.

https://doi.org/10.11628/ksppe.2013.16.6.353

Lee, M.S., H.Y. Kim, J.E. Shin, and J.H. Ku. 2008. Effects of horticultural therapy on the adaptation behavior and durability of student in special school. J. Korean Soc. People Plants Environ. 11(2):55-64. 
Lee, Y.J. 2008. Effects of gardening activity on self-respect and psychological sociability of the auditory disabled person. Master's thesis, Seoul University, Seoul, Korea.

Lim, H.S. and S.C. Park. 2016. The effect of horticultural therapy on reducing depression and increasing self-esteem of elderly audition disabilities. J. Korea Entertain. Ind. Assoc. 10(4):225-235. https://doi.org/10.21184/jkeia.2016.08.10.4.225

Malchiodi, C.A. (Ed.). 2003. Handbook of art therapy. New York, NY: Guilford Press.

Ministry of Health and Welfare. 2017. 2017 Survey of the disabled. Sejong, Korea: MHW.

Noh, Y.J. and N.Y. Kim. 2008. The effects of dance/movement therapy on the self-expression and school adjustment of hearing impaired children. J. Psychother. [Seoul Women's University] 8(1):149-166.

Oh, C.G., J.J. Chung, and E.L. Kim. 1999. The study on preference for flower color of the mentally retarded and hearing impaired student. J. Korean. Soc. People Plants Environ. 2(3):6-12.

Park, E,J., J.I. Yoon, and Y.K. Yoo. 2006. Effects of horticultural therapy on the psychological and emotional behavior in a mentally retarded person of island region. J. Korean Soc. People Plants Environ. 9(2):31-37.

Ra, S.H. 2001. Effect of the horticultural activities in leisure on the changes of depression, life satisfaction and small muscles of old woman. Master's thesis, Konkuk University, Seoul, Korea.

Relf, P.D. and V.I. Lohr. 2003. Human issues in horticulture. HortScience 38(5):984-993. https://doi.org/10.21273/HORTSCI.38.5.984

Sin, E.S. and M.J. Lee. 2010. Horticultural therapy program on sociality and emotional behavior of the developmental disabled children. J. Korean Soc. People Plants Environ. 13(6):9-16.

Son, H.J. 2003. A study on the factors that affect on the social and emotional development of the hearing handicapped students. Master's thesis, Catholic University, Daegu, Korea.

Song, M.J. 2013. Evaluation of horticultural therapy on the depressed patients by bio-signal. Doctoral dissertation, Seoul University, Seoul, Korea.

Woo, H.I. 2012. The effect of the depression and subjective happiness on the self-esteem of female aquarobics exercise participant. Korean J. Sport Psychol. 23(4):155-164.

Yoon, K.E., M.H. Kang, U.H. Kim, M.A. Jang, H.S. Huh, W.S. Yoon, and M.H. Jang. 2003. Effect of exercise, arts and horticultural therapy on the changes of sociality of the children's developmental disability. J. Korean Soc. People Plants Environ. 6(3):11-18.

Yun, S.Y., B.J. Choi, and H.Y. Kim. 2009. The effects of flower arrangement on the balance of feelings and depression of hospitalized elders. J. Korean Soc. People Plants Environ. 12(6):1-5.

Zung, W.W. 1965. A self-rating depression scale. Arch. Gen. Psychiatry 12(1):63-70. https://doi.org/10.1001/archpsyc.1965.01720310065008 